\title{
Unfolding What Self-Compassion Means in Young Carers' Lives
}

\author{
Yana Berardini $^{1} \cdot$ Heather Chalmers ${ }^{1} \cdot$ Heather Ramey $^{1}$ \\ Accepted: 29 August 2021 / Published online: 4 September 2021 \\ (C) The Author(s), under exclusive licence to Springer Science+Business Media, LLC, part of Springer Nature 2021
}

\begin{abstract}
Young carers (YCs) are children and youth who provide caregiving for family members who may experience an illness, disability, addiction, language barriers, and/or age-related needs. Many of them show compassion towards others and continue to put their family members' needs before their own. They also report having no time for other activities or for themselves due to the caregiving role. Self-compassion might allow YCs to be kind to themselves, be mindful of their emotions, and understand that others, like them, go through similar experiences. While the relationship between outward and inward compassion has been examined in past research, studies have yet to determine YCs' self-compassion level in the context of providing care for others. The purpose of this qualitative study was to gain a better understanding of what compassion and self-compassion meant for YCs and whether they saw themselves as self-carers in addition to being caregivers. Six focus groups with YCs ages 12 to 18 years $(n=33)$ were conducted. Eight boys and 26 girls were divided into younger and older focus groups. A constant comparison analysis yielded three major themes: characteristics of compassion, self-compassion in YCs, and supports for self-compassion. Overall, YCs showed continual compassion for their loved ones, but despite understanding the value of self-care and self-compassion in one's lives, very few YCs displayed self-compassion. Some reported conflicts and tensions within them and between them and their family member(s). The role of parents and YC programs were addressed as a possibility for supporting self-compassion.
\end{abstract}

Keywords Self-compassion $\cdot$ Young carers $\cdot$ Compassion $\cdot$ Self-care $\cdot$ Focus groups

Young carers (YCs) show continuous compassion by seeing and supporting their loved ones' vulnerabilities, showing sensitivity, and attending to their needs (Berardini et al., in press; Dewar et al., 2014; Sahoo \& Suar, 2010). These young people, usually between the ages of $12-29$, provide care for family members due to specific circumstances in their family (e.g., illness, disability, addiction, language barriers, age-related needs, and parental absence) (Bleakney, 2014; Charles, 2011; Charles et al., 2009; Stamatopoulos, 2015). While YCs are slowly gaining recognition in North America, the impact of this caregiving role and how it manifests in their lives has yet to be fully understood, in part due to mixed findings.

In general, caregiving seems to be associated with some costs or, as Stamatopoulos (2018) described it, 'a young

Yana Berardini

ylakm064@gmail.com

1 Department of Child and Youth Studies, Brock University, 1812 Sir Isaac Brock Way, St. Catharines, ON L2S 3A1, Canada carer penalty', which can include emotional, psychological, social, and educational disadvantages (Lakman \& Chalmers, 2019; Lakman et al., 2017; Metzing-Blau \& Schnepp, 2008; Moore et al., 2009; Nagl-Cupal et al., 2014). Previous studies showed that some YCs experienced depression, low self-esteem, poorer health, as well as lower levels of life satisfaction, happiness, and well-being (Banks et al., 2002, Banks et al., 2001; Chalmers \& Lucyk, 2012; Collins \& Bayless, 2013; Hamilton \& Adamson, 2013; Lakman \& Chalmers, 2019; Lloyd, 2013; Thomas et al., 2003). Yet, when taking into consideration YCs' outlook on life, some positive outcomes become noteworthy. When YCs found benefits in their role as a carer, they experienced more positive outcomes (e.g., in their social lives, with their family, and in their education) and less burden from care, thus more resilience (Areguy et al., 2019; Cassidy \& Giles, 2013; Gough \& Gulliford, 2020). Additionally, having practical coping strategies (Doutre et al., 2013; Polkki et al., 2004) or a strong sense of agency and connectedness (Gough \& Gulliford, 2020) also promoted better outcomes for YCs. 
To our knowledge, one factor that has not yet been explored in caregiving youth is self-compassion. In this study, self-compassion is a kindness that is directed inwards and could be seen as a healthy attitude or a coping strategy used when life becomes difficult (Neff, 2003a, 2003b). Selfcompassion involves people showing kindness toward the self (self-kindness), becoming mindfully aware of negative emotions (mindfulness), and understanding that experience is not unique, but common to all human beings (common humanity) (Neff, 2003a, 2003b). It is highly related to selfcare; self-compassion can fall under 'self-care' as a strategy to care for the self (Andrews et al., 2020; Coleman et al., 2016; Macedonia, 2018; Mills, 2018) or be predicted by self-care (Coleman et al., 2016; Macedonia, 2018; Mills, 2018). What makes self-compassion relevant to caregiving is its relationship to other-oriented care. People who mostly show outward compassion can have lower self-compassion (Andrews et al., 2020; Neff, 2003a). This other-oriented caregiving has been found to relate to 'compassion fatigue' (e.g., job-related stress) (Coleman et al., 2016; Figley, 2002; Mills et al., 2018), as well as burden and stress (Sawatzky \& Flower-Kerry, 2003; van Groenou et al., 2013; Williams et al., 2014a, 2014b). In many cases, those who care for others do not have many opportunities to self-care (Acton, 2002).

In YCs' situations, although the relationship between inward and outward compassion has not yet been directly examined, some evidence points to their limited ability to self-care. Past studies have shown that self-care was the least engaged in activity by YCs (Lakman, 2015) and that caregiving for others was a major stressor in that YCs had little time to themselves and had few breaks from the caregiving role (Sexton, 2017; Stamatopoulos, 2018; Szafran et al., 2016). Some YCs reported suppressing their own emotions while showing compassion towards their loved ones (Ali et al., 2012; Chan \& Chau, 2010). A study by Nagl-Cupal and colleagues (2015) found that only after YCs exited their role as a caregiver, did they notice that their own needs had been set aside for a long time. This suggests that YCs may not have time nor the opportunity to be compassionate towards themselves due to the needs of their loved ones. Therefore, in the context of caregiving for others, in which YCs spend numerous hours (Banks et al, 2001; Moore et al., 2009; Nagl-Cupal et al., 2014; Warren, 2007), they might have limited time to self-care or show self-compassion.

Lower self-compassion may have some impact on YCs' lives. Having the ability to learn and show self-compassion has been associated with many benefits, such as increased social connectedness (Neff \& McGehee, 2010), greater life satisfaction (Neff, 2003a), as well as higher optimism and happiness (Neff et al., 2007). Thus, it is vital to understand YCs' perceptions of their self-compassion in the context of caregiving for others and in relation to self-care. Since YCs' current levels of self-compassion remain unknown, the current study's objectives were three-fold: (1) to gain a better understanding of what compassion meant for YCs and (2) to examine what self-compassion means to YCs and (3) to explore whether YCs saw themselves as self-carers in addition to being caregivers. This information could be used to enhance some services and programs directed to improving YCs' well-being.

\section{Methods}

\section{Design and Sampling}

Following ethics approval from the authors' affiliated university, participants were recruited from two YC organizations in Southern Ontario, Canada. At the time of the study, one young carer program supported 179 YCs between the ages of 5-17 years. YCs provided care for a parent, grandparent, sibling, or relative with chronic or life-threatening illness, disability, addiction, mental illness, or language barrier (Hospice Toronto annual report 2018-2019). The second program supported 712 clients. Of those, 372 were parents and 340 were children (YCs). Approximately 50\% of YCs cared for multiple family members and for multiple reasons. The majority (41\%) cared for someone with a disability (Lewis, 2019).

By using purposive sampling techniques, executive directors and staff at the two YC organizations were contacted. Participants self-identified as YCs and attended these programs. Participants were self-identified as YCs by family members or professionals (i.e., service providers). Once the participants' signed parental consent forms were returned to the service providers, a focus group session was scheduled. Between August 2019 and November 2019, six focus groups were conducted in two urban settings and one rural setting. The sample primarily consisted of white individuals.

To strengthen qualitative rigor, the researchers followed guidelines for qualitative research set by Tong and colleagues (2007) and Miles, Huberman, and Saldana (2019). For instance, the researchers ensured that each identified theme was illustrated with quotations (Tong et al., 2007). To further promote rigor, researchers also paid attention to the number of participants within each group. It was recommended that four to seven participants were in each of the six focus groups (Kitzinger, 2005; Liamputtong, 2011). Focus groups were divided into younger and older age groups to offset any possible developmental differences within one group (Krueger, 1994). Upon arrival, the participants signed an assent form and were encouraged to ask for clarifications at the start of the focus group. All participants gave permission to be audio recorded. At the beginning of each focus group, the researcher introduced the topic and defined the 
main construct of self-compassion as aligned with Neff's (2003a, 2003b) conceptualizations. On average, the focus groups ran for approximately $40 \mathrm{~min}$, with a range of $30 \mathrm{~min}$ to approximately one hour. Semi-structured questions pertained to how participants defined compassion versus selfcompassion, what minimized self-compassion, how it tied to well-being, and parents' role in promoting it. At the end of each focus group, participants were provided with pizza and soft drinks.

\section{Data Analysis}

This study utilized content analysis, specifically thematic analysis, as a theoretical framework (Braun \& Clarke, 2006; Tong et al., 2007). As part of these analyses, the authors chose constant comparison analysis (Onwuegbuzie et al., 2009). First, data was chunked into smaller units, representing a code. Then, codes were grouped under similar categories. Finally, themes were created to encompass the categories (Onwuegbuzie et al., 2009). Then there was a comparison of the first group to the rest, to see if the themes in the first group were also observed in subsequent focus groups (Onwuegbuzie et al., 2009). Coding for themes was done following a hybrid approach that included both deductive and inductive thematic analysis (Fereday \& MuirCochrane, 2006). The groups were analyzed in an aggregate form, while still paying close attention to any potential developmental differences between younger and older youth. Any relevant and noteworthy findings regarding group differences were discussed in each theme. Four research team members examined the codes to ensure consistency across the codes under each theme. The inter-coder agreement, a code cross-checking technique, was $96.4 \%$. Any discrepancies were resolved by full discussions among the four research members. The researchers continued to analyze the data until no new themes were identified.

\section{Results}

This study examined whether YCs saw themselves as selfcarers in addition to being caregivers and whether they engaged in self-compassionate behaviours in the context of providing care to others. Overall, there were $N=33$ participants ages 12 to $18 ; 16$ participants ( $n=2$ male, $n=14$ females) were 12 to 14 years of age (younger group) and 17 participants ( $n=6$ male, $n=11$ female) were 15 to 18 years of age (older group). For an age and gender composition across the groups, please see Table 1 . The results revealed three main themes: Characteristics of compassion, self-compassion in YCs, and supports for self-compassion.
Table 1 Composition of age and sex across the focus groups

\begin{tabular}{lllll}
\hline $\begin{array}{l}\text { Focus } \\
\text { group \# }\end{array}$ & Location & Gender spit & Age range & Younger/Older \\
\hline 1 & Location 1 & 1 male; 5 female & $12-13$ & Younger \\
4 & Location 1 & 2 male; 4 female & $15-18$ & Older \\
2 & Location 2 & 0 male; 5 female & $12-14$ & Younger \\
5 & Location 2 & 3 male; 4 female & $15-18$ & Older \\
3 & Location 3 & 1 male; 5 female & $12-14$ & Younger \\
6 & Location 3 & 1 male; 3 female & $15-18$ & Older \\
\hline
\end{tabular}

\section{Characteristics of Compassion as a Function of Being a YC}

This study revealed that YCs spoke about their responsibilities in task-oriented versus affect-oriented compassion. Furthermore, compassionate care promoted positive selfregard and regard for others (see Table 2 for themes and example quotations). The task-oriented compassion included any behaviours that were intended to solve a problem, such as helping others with speech, lifting, doing groceries, and completing household tasks. The affect-oriented compassion comprised any behaviours that were specific to showing emotional care, such as giving someone a hug, being there for their loved ones, and emotionally checking in on them. Affect-oriented compassion included acts of empathy. When asked what compassion meant for the participants, a younger female participant noted that for her, it was about "putting yourself in someone else's shoes and letting yourself feel what they are feeling" [focus group 2].

Further, compassionate actions contributed to positive self-regard, or an improved perspective of how they saw themselves. As one participant commented: "It [providing care] makes you feel more mature. It makes you feel like smarter, more mature, cuz you are helping someone out" [focus group 3, younger female]. All younger participants (and none of the older ones) gave an adjective to describe how helping others made them feel (e.g., happy, excited, good, amazing). The older youth were far more reflective about how these actions made them feel, which could simply be due to developmental differences. This was illustrated as one older male [focus group 5] stated:

“... it [showing compassion] can be very stressful but at the same time, it can be a very good thing cuz it's one of those things that pushes me to be more optimistic towards others and help others...you just feel like you [are] doing something for the best of the world... helping other people and make sure they are not in the same spot that you were kind of makes you feel good".

In addition to gaining a more positive state of self, compassionate actions elicited regard for others, as many more 
Table 2 Themes and example quotations for theme A: characteristics of compassion

\begin{tabular}{|c|c|c|}
\hline Themes & Subthemes & Example quotes \\
\hline \multirow{5}{*}{$\begin{array}{l}\text { A. Charac- } \\
\text { teristics of } \\
\text { compassion }\end{array}$} & 1. Task-oriented & "When my father is feeling down, I play chess with him" [focus group 1, younger male] \\
\hline & $\begin{array}{l}\text { 2. Affect-oriented } \\
\text { 2.1 Empathy }\end{array}$ & $\begin{array}{l}\text { "When my older sister feeling down, I try to cheer her up" [focus group 1, younger } \\
\text { female] } \\
\text { "...I can also have empathy for them and give them advice. I can be like 'okay, I kind of } \\
\text { went through something similar, last year, and for me, this really helped', you know?" } \\
\text { [focus group 4, older female] }\end{array}$ \\
\hline & 3. Contributes to positive self-regard & $\begin{array}{l}\text { "It makes me feel good because it lets me know that I did a good thing" [focus group } 2 \text {, } \\
\text { younger female] }\end{array}$ \\
\hline & 4. Promotes regard for others & $\begin{array}{l}\text { "My sister is upset a lot, so it makes me happy to see her happy" [focus group 1, } \\
\text { younger female] }\end{array}$ \\
\hline & 5. A normal action, not special & $\begin{array}{l}\text { “...but you did it everyday so its not really something you notice... you are just like } \\
\text { 'okay, take your medicine'. And you don't really feel for that anymore cuz you have } \\
\text { done it for flipping } 16 \text { years, right?” [focus group } 4 \text {, older female] }\end{array}$ \\
\hline
\end{tabular}

participants reported caregiving because it made the other person feel good. As one younger, female participant stated [focus group 1]: "[caregiving makes me] happy to see my brother happy even though it bugs me a lot, I still want to see my brother happy".

Finally, for some of the older youth (and none of the younger participants), compassion was not a special act at all (see Table 2). In fact, older YCs talked about how for them it was a normal, "natural" act, as one participant described:

"It's just like... for me... I dunno if it's for the others,
but like doing the things that you need to do for the
person you care for is just natural, right? Like by now,
at the stage we are at [mumble], it's kind of a fluid
motion. It's like muscle memory. You just go with it or
whatever. I know when I was younger and when I first
started putting this extra step, you kind of feel good
about yourself, you feel like 'oh, I helped someone
out today' or whatever..." [focus group 6, older male].

\section{Self-Compassion in YCs}

\section{The Paradox and the Struggle with Self-Compassion}

In the current study, YCs understood self-compassion as being an essential part in their caregiving identities (see Table 3 for subthemes and example quotations). For instance, one participant said: "I mean self-caring makes me feel like a better person because I became kinder and more accepting [towards her brother] by self-caring" [focus group 6, older female]. When asked how they showed selfcompassion or self-care, many YCs were able to list selfcaring practices. They shared how they watched TV, surfed the Internet, hung out with friends, took baths, and relaxed.
Despite verbally stating its' essential role and bringing up self-caring ideas, a contradiction appeared when they identified that the caregiving role was their main barrier to self-compassion, as one participant commented:

"You have to take some time out of your day. It can be very time consuming and energy consuming and emotionally consuming... just like very consuming everything... even if you might not notice it. Because what if this person [the person they care for] wasn't this way, like you would maybe have more time for other things" [focus group 3, younger female].

Some tensions related to confusion or lack of understanding of self-compassion (see Table 3). When asked whether they had time to care for themselves or show self-compassion, some simply nodded in agreement. When asked to elaborate on how they did it, a younger female participant responded: "I don't really make... I don't know... I just... it's... I don't know" [focus group 1].

Further conversations with YCs revealed that it was very hard for some older YCs to accept the need for self-care or self-compassion. Older YCs spoke about how it would make them feel selfish if they took the time away from their loved ones to care of themselves. To truly understand the tensions between being a YC and having time to self-care, an older female participant said: "It's difficult to care for yourself" [focus group 4]. To which, another member of the group added: "Yea, cuz there is a very fine line between self-compassion and selfishness...very fine line and I don't want to cross it... I rather not have self-compassion than be selfish" [focus group 4, older male].

Finally, some tensions grew out of sense of guilt for taking time for themselves instead of helping others. These tensions were further explained by a participant who said: "You have the ability to care for yourself but you do feel kind of 
Table 3 Themes and example quotations for theme B: self-compassion in YCs

\begin{tabular}{lll}
\hline Themes & Subthemes & Example Quotes \\
\hline
\end{tabular}
\begin{tabular}{lll}
\hline $\begin{array}{l}\text { B. Self- } \\
\text { compassion }\end{array}$ & $\begin{array}{c}\text { 1. The relationship between self-compas- } \\
\text { sion and caregiving- The paradox }\end{array}$ & $\begin{array}{c}\text { 1.1. Self-compassion is essential to be a } \\
\text { good caregiver }\end{array}$
\end{tabular}

in YCs

\subsection{Self-compassion via self-care practices \\ 1.3. YCs' caregiving responsibilities directly minimize self-compassion}

2. The struggles and tensions
2.1. YCs did not think about or understand the term

2.2. YCs worried that it may reflect selfishness

\subsection{YCs felt torn}

2.4. YCs felt guilty

3. Pointers toward lower self-compassion
3.1. Increased compassion for others

3.2. Increased self-judgement
"If you are feeling bad it would be pretty hard to help other people, because how can we care for other people if you are not caring for yourself?"' [focus group 2, younger female]

"I sometimes like to draw so I would draw" [focus group 1, younger female]

"For me, its hard to find the time because my brother, he doesn't communicate like others do so it gets tough to like stay on top of school and I sort of fear for my future like university... like how am I going to help my parents but typically, I try to find the time. Sometimes I just don't have the time" [Focus group 6 , older female]

"I don't have any self-compassion" [focus group 4, older male]

"I never actually even thought of thatwow!" [focus group 4, older female]

"I would consider myself selfish if I did that. Oh, it's like 'am I allowed to do all of this for me?'. It's for me... it's not for someone else... if I pay attention to them [family member], am I allowed to give this much attention to me?" [focus group 6 , older female]

"For me, its like, I guess its like stress. Like I'm stressed... my brother is growing up and... he needs more help right now to become more independent and stuff, as he gets older, its going to get worse. And I'm like 'but I have my own stuff in life that I also have to care for'" [focus group 4, older female]

"I guess if you don't care for them I guess its in the back your mind, there is a little tick that kind of reminding you but yea, you know, there are times where us, as caregivers, we should be able to have a little bit of time alone, or not time alone, time away from having that responsibility.. but yea" [focus group 6, older male]

"No [don't have time to self-care]. If I do have any free time, I immediately ask if anybody needs help, cuz I know they need help more than I do" [focus group 4 , older male]

"yea I don't tell my parents when things get hard. I don't ..." [focus group 6, older female]

“...Even if I facetiming...they are like 'oh [name] you seem like such a good sister', but like I don't see it. I don't know if its just me" [focus group 4, older female] 
Table 3 (continued)

\begin{tabular}{|c|c|c|}
\hline Themes & Subthemes & Example Quotes \\
\hline & $\begin{array}{l}\text { 3.3. Increased overidentification with } \\
\text { emotions }\end{array}$ & $\begin{array}{l}\text { "I go outside and yell" [focus group } 2 \text {, } \\
\text { younger female] }\end{array}$ \\
\hline & $\begin{array}{l}\text { Externalization/internalization } \\
\text { versus } \\
\text { acceptance }\end{array}$ & $\begin{array}{l}\text { "I get stressed out because sometimes } \\
\text { when I'm working too hard, some days } \\
\text { I kind of run myself to the ground and } \\
\text { then I get really tired and my emotions } \\
\text { are all over the place. I dunno... it } \\
\text { stresses me out most of the time" [focus } \\
\text { group 5, older female] }\end{array}$ \\
\hline & & $\begin{array}{l}\text { "Just go on with life and just not do it } \\
\text { [self-care]. You live and you will be fine } \\
\text { eventually at some point.... Hopefully" } \\
\text { [focus group 4, older male] }\end{array}$ \\
\hline & $\begin{array}{l}\text { 3.4. Decreased isolation via common } \\
\text { shared experiences }\end{array}$ & $\begin{array}{l}\text { “... Of course we go through different } \\
\text { situations at home and you have some } \\
\text { similarities, they won't find it in a school } \\
\text { building necessarily" [Focus group } 5, \\
\text { older female] }\end{array}$ \\
\hline
\end{tabular}

slightly selfish or self-centred so then you kind of lay back and you care for yourself but not as much as you thought you could" [focus group 6, older male].

The following exchange with participants [focus group 5] and the researcher helps to show how difficult it could be for some YCs to take time during their day for self-care:

"I probably do [have time to self-care], I just don't take it though... you can and you know how to, but you just don't feel you need it. You just want to 'save it for another time"" (older female). To which another participant added, "yea that is what I was just thinking, more than likely a lot of people have time but choose not to use it ... probably the feeling of you can't'. (older male).

\section{Pointers Toward Lower Self-Compassion}

Results from the focus groups indicated that YCs' self-compassion was notably low given their other-oriented tendencies, self-judgement, and overidentification with emotions. Yet, evidence pointed to aspects of common humanity, which is an integral part of self-compassion (see Table 3).

\section{‘Other Oriented' Tendencies}

YCs' responses were extremely 'other-oriented'. In this study, some quotes illustrated that for them, even self-care was rooted in other-oriented care. A younger female participant [focus group 1] said that self-compassion is "that you love yourself, doing the best you can for anyone" and an older, male participant [focus group 6] responded: "hmm care for myself, I'd say its caring for them too". Further, all older YCs (and none of the younger ones) reported concealing their 'need for self-care' from their parents to protect them from added stress. As one participant reported:

"I think my parents think... yea... they think that I take care of myself a lot, right? But I don't... my parents are like 'how has your day been [participant's name]?' and 'are you taking care of yourself and stuff?' and I'm like 'yes, of course I am!', but that's A BIG FAT LIE [emphasized and pronounced louder]. And I just don't want them to worry cuz they already have enough to worry about" [focus group 4 , older female].

\section{Self-Judgement}

YCs in the current study did not show self-kindness. In fact, when they were asked whether they were good carers, some narratives pointed to self-judgement, as participants said 'no' and one participant reported: "they [grandparents with whom he lived] kicked me out so I couldn't have been that good" [focus group 4, older male]. Although exploring the reasons for this was beyond the purpose of this study, the YC might have thought that if he were a better carer, they would not have 'kicked' him out. This self-criticism may hinder YCs' ability to be kind to themselves, thereby lowering their levels of self-compassion.

Another example came from a younger female participant, who distinguished between feeling good about herself physically versus mentally, as she responded: “...because physically I would...I do take care of myself. I like makeup and everything but like mentally, I'm not really nice to myself" [focus group 3]. 


\section{Overidentification with Emotions}

YCs' quotes exhibited the consequences for lacking time to self-care, which suggested overidentification with emotions. Both younger and older participants reported negative affect when they sensed that they did not have time for self-care (please see Table 3 for example quotes). Interestingly, the younger participants reported externalizing behaviours (e.g., getting upset, yelling, and freaking out), while the older participants reported more internalized stress.

Meanwhile, some participants reported accepting the fact they had no time for self-care or self-compassion. For example, an older female participant responded [focus group 6]: "I try to think that its okay sometimes if I miss one time with my friends, sometimes I'll see them at school the next day and we will be fine".

\section{Common Humanity}

Being a part of a support program engendered a sense of belongingness, rather than isolation. Many participants in the current study talked about the importance of having friends who shared their experiences, as one participant noted: "I think coming here also takes off of the stress at home so we just have fun hanging out with people who are going through the same thing as us" [focus group 1, younger female].

\section{Supports for Self-Compassion}

Both parents and the support programs played a role with respect to self-compassion (please see Table 4 for example quotations). Some participants spoke about their parents' ability to encourage and promote self-compassion in them. For example, an older female participant said "My parents sometimes when I'm doing too much, they will be like... they will say that its not all my responsibility to take care of everything and that if I want to go away to some place, yea that's fine" [focus group 5]. Yet, others shared that their parents disapproved when they took time for themselves. The following exchange between the researcher and two participants showed that some parents were unable to give YCs the break that they were looking for:

Researcher: "Have they [parents] ever come to you and said 'listen, I know you are going through a lot, have a little break"'.

Participant [focus group 5, older female]: "oh no, they will add stuff on my plate and expect me to be done in

Table 4 Themes and example quotations for theme C: supports for self-compassion

\begin{tabular}{|c|c|c|c|}
\hline \multicolumn{2}{|l|}{ Themes } & \multirow{2}{*}{$\begin{array}{l}\text { Subthemes } \\
1.1 \text { Parents encourage }\end{array}$} & \multirow{2}{*}{$\begin{array}{l}\text { Example Quotes } \\
\text { "My parents think self-compassion is really good for me and } \\
\text { they help me a lot" [focus group 2, younger female] }\end{array}$} \\
\hline $\begin{array}{l}\text { C. Supports for } \\
\text { self-compas- } \\
\text { sion }\end{array}$ & $\begin{array}{l}\text { 1. Parent's role } \\
\text { in relation to } \\
\text { self-compas- } \\
\text { sion }\end{array}$ & & \\
\hline & & 1.2. Parents disapprove & $\begin{array}{l}\text { "Not at all! Whenever I try to have anytime to myself they just } \\
\text { immediately get mad at me for no reason" [focus group } 4 \text {, } \\
\text { older male] }\end{array}$ \\
\hline & & 1.3. Parents expect or assume they are fine & $\begin{array}{l}\text { "When I get home, its kind of spaced out when it comes to my } \\
\text { parents. I have dinner or whatever, but then I go do my own } \\
\text { thing. They are not like checking in and being like 'hey, are } \\
\text { you okay? We know you have to take care of her, how are } \\
\text { you doing?' It's kind of like 'do it'. Its just how it is" [focus } \\
\text { group 6, older male] }\end{array}$ \\
\hline & & 1.4. Increased conflicts with parents & $\begin{array}{l}\text { “...let's say I spent over an hour on my phone, my mom, she } \\
\text { wouldn't get super mad at me about it but...be like 'oh you } \\
\text { should be spending time with your brother, like you are wast- } \\
\text { ing all this time on yourself, but you should be spending it } \\
\text { with your brother'...its like a mix... other times they are like } \\
\text { '[participant name], you have been way too involved in other } \\
\text { things, take a day off'. So, I don't know how it works...” } \\
\text { [focus group 4, older female] }\end{array}$ \\
\hline & $\begin{array}{l}\text { 2. Program's } \\
\text { role in relation } \\
\text { to self-com- } \\
\text { passion }\end{array}$ & 2.1 Escape & $\begin{array}{l}\text { "It feels like I have the time off and I don't have to watch them } \\
\text { [siblings] because someone else is there to watch them" } \\
\text { [focus group 2, younger female] }\end{array}$ \\
\hline & & 2.2 Learn skills & $\begin{array}{l}\text { "they teach you ways to care for yourself" [Focus group } 1 \text {, } \\
\text { younger female] }\end{array}$ \\
\hline
\end{tabular}


two hours". To which another participant [older male] exclaimed: "precisely!"

Other participants noted how their parents expected things to get done or assumed they were okay, as one participant reported: "my parents care about me, but most of the time they spend on my sister, especially my mom. She does the cooking and works so she doesn't have a lot of time to check up on me and she assumes I'm very independent" [focus group 6, older female]. In fact, one YC [focus group 6 , older female] noted that her parents forget to check up on them because "they have their own problems...they don't always know what you are doing so you get home, and you go upstairs and you work on your own stuff and they think 'oh you always caring about yourself'".

Finally, some narratives revealed an increased conflict with parents regarding self-compassion, as one younger female participant shared: "Sometimes my mom lets me but sometimes she doesn't. The times that she doesn't, I get really angry easily, and then I start getting mad and I start yelling, and then she starts yelling at me and then I get in trouble" [focus group 2]. Other times, the conflict was brought up because parents and YCs had different ideas about what self-care entailed. One participant reported: "when they [parents] think of 'caring for yourself', my mom especially thinks of exercising, like 'you should go exercise or something', rather than... I feel like there are other forms of self-care that aren't always exercise" [focus group 4, older female]. For this participant, self-care was more about a distraction or relaxation.

In addition to parent's role in shaping self-compassion, support programs also found ways of promoting it by giving participants opportunities for socializing with other YCs and learning new skills (see Table 4 for example quotations). When asked about their experiences with the support programs they were a part of, many participants noted how they used the programs to escape and felt relief from their caregiving role. Some participants reported that the programs taught them not only how to care for the self, but also how to care for others, as an older male participant [focus group 6] claimed: “...we have programs like this to share or gain more knowledge on how to take care of them...". Most importantly, programs were able to offer peer support, which in turn offered YCs the opportunity of engaging with and learning from other YCs. This study found that many of them liked being friends with other YCs.

\section{Discussion}

Although it is common for several studies to categorize YCs' caregiving into household tasks, medical care, sibling care, personal care, and emotional care (Chan \& Chau, 2010; Fives et al., 2013; McDonald et al., 2009; Sahoo \& Suar, 2010; Sexton, 2017; Warren, 2007), this study found that caregiving can be divided into two facets: task and affectoriented care. In other words, YCs may engage in actions that solve a problem or provide emotional care for their loved ones. Some youth also mentioned compassion as form of an empathy. The role of empathy in providing care was not explored within this study and should be explored in future studies, as it may be either a trait that could predict compassion (Lim \& DeSteno, 2016), or be the product of such caregiving (Stamatopoulos, 2018).

It was interesting that this study found caregiving actions enhanced positive self and others' regard. This was congruent with previous studies that reported that caregiving contributed to some YCs feeling happier, becoming stronger, as well as becoming more considerate, mature, compassionate, proud, capable, and useful (Bolas et al., 2007; Chan \& Chau, 2010; Sahoo \& Suar, 2010; Smyth, et al., 2011a, 2011b; Szafran et al., 2016). In the present study, older YCs explicitly stated that compassion not only enhanced their self-regard (e.g., made them more optimistic, made them feel good), but it also promoted regard for others (e.g., become optimistic to help others, making sure others are doing well). Similar trends were found by Bolas and colleagues (2007), where interviews with older youth (aged 14 to 18) showed that their sense of self-esteem was tied to feelings of being useful and capable of helping others. This could be tied to why certain children and youth choose to provide care. For instance, Berardini and colleagues (in press) have suggested that some YCs could be motivated by evolutionary mechanisms (e.g., kin selection, altruism, attachment, and temperament) to care for others in the family. The motivator may be as simple as loyalty and love for family members (Earley et al., 2007), but it could also be self-serving (Berardini et al., in press). However, it must be noted that in many cases, YCs do not have a choice when it comes to caring for their loved ones (Bolas et al., 2007; Parveen et al., 2011; Sawatzky \& Fowler-Kerry, 2003; Smyth, et al., 2011a, 2011b). Therefore, future studies could further explore this "involuntary" or "subconscious" nature of compassion.

Whether compassion enhances one's state or promotes regard for others, or both, at the same time, it can also become normalized. This may suggest that doing it for longer (as a function of being older) makes acts of compassion less noticeable and less unique with time. This finding was complemented by McDonald et al. (2010) who found that for some YCs, caregiving became a natural behaviour, 
and with time, both parents and children have gotten used to it. However, it should be noted that habituating to the caregiving role could just be a function of how they have entered the role and the length of time they care for. In other words, those who reported it was normal for them could have been socialized into the role (e.g., have been born into it), and since they started caregiving at an earlier age, it was all they knew (Hamilton \& Adamson, 2013; McDonald et al., 2010; Smyth et al., 2011a, 2011b). The ability to provide caregiving "naturally" could also indicate temperamental differences that other children and youth may not possess (Lakman \& Chalmers, 2019). Another potential explanation, and perhaps a more problematic view, is that with time and increased complexity of the caregiving situation, these young people may think more and more about their family member(s)' needs and less and less of their own (Nagl-Cupal et al., 2015).

In an attempt to understand the link between self and other-oriented compassion, this study also examined the role of self-care in the context of caring for others. In this study, YCs listed self-care practices, but had trouble with self-compassion; despite considering it essential to their lives, they reported to lack the time for it. It was not surprising that YCs experienced time constraints (Banks et al., 2002; Stamatopoulos, 2018; Warren, 2007), but these results have expanded previous studies because they point to the relevance of time availability in relation to self-compassion and the ability to self-care. In this context, it created a paradox: YCs knew that self-compassion was important to their caregiving role, were able to list self-care practices, but reported that their caregiving role is one barrier to selfcompassion and self-care.

This paradox yielded some tensions. For instance, some YCs could not explain how they showed self-compassion, either because they never thought of it before or because they experienced difficulty with the 'self-compassion' term. The silence of the rest of the participants could suggest that they did not understand the topic, were uncomfortable with the topic, or wanted to avoid answering the question. For others, especially for older YCs in this study, self-care was equivalent to a character flaw. It should be noted that developmentally, older youth were in the stage of being highly concerned with how others might perceive their behaviours, and as a result they might have been more concerned with how it would look if they cared for themselves instead of for their loved ones. Even though previous research noted that selfcompassion did not relate to narcissism (Mills et al., 2018; Neff \& Vonk, 2009; Neff, 2003a) and did not entail selfishness or self-centredness (Mills et al., 2018; Neff, 2003a), some YCs continued to struggle with distinguishing between self-compassion and selfishness. Finally, some YCs spoke about feeling guilty taking off time for self-care or self-compassion. This was in accordance with previous studies that showed the role that guilt plays in caregiving (Bolas et al., 2007; Doutre et al., 2013; Earley et al., 2007; Stamatopoulos, 2018). In a recent study, for example, Stamatopoulos (2018) found that several older YCs (ages 15 to 19) reported that it was difficult to secure "free time" and even if they were successful, they felt guilty for taking it. These feelings and tensions are not unique to YCs. For example, informal and formal adult caregivers also noted similar tensions, and feelings of being selfish or feeling guilty (Gonyea et al., 2008; Mills et al., 2018; Tate, 2015). Future studies could further explore how the existence of these tensions, especially guilt, can minimize one's self-compassion.

In sum, this study found that YCs showed low self-compassion. The current study found that YCs showed more "other-oriented" tendencies, suggesting that some YCs were oriented towards helping others more so than helping themselves, thereby diminishing their self-compassion (Neff, 2003a). Some even chose to actively conceal their hardships as an attempt to protect their parents from added stress, reinforcing again their 'other-oriented' tendencies, despite the potential costs to themselves. This tendency was evident in other studies who found that YCs suppressed their needs to ensure others' needs were met first (Ali et al., 2012; Nagl-Cupal et al., 2015). Recently, Stamatopoulos (2018) found that YCs' needs were secondary to the needs of their family member(s). Thus, this inclination of thinking about others first before meeting their own needs reinforced just how potentially low their self-compassion level was.

Other pointers toward low self-compassion included narratives of some YCs who were critical of themselves at times. Similar findings were reported in a study by Ali and colleagues (2012) who found that some YCs felt that they were hindering the situation with their care-recipients, especially when they felt that the person for whom they cared for resented them for caring for them. This self-judgement (e.g., feeling as inadequate caregivers or thinking that they have failed to meet the care recipient's needs) could be associated with one's guilt (Gonyea et al., 2008; Losada et al., 2010), thereby pointing again to its' potential influence over self-compassion.

In addition to self-judgemental tendencies, a number of YCs reported being overidentified with emotions, which is indicative of low self-compassion (Neff, 2003a). Similarly, Szafran and colleagues (2016) found that YCs acted out and engaged in illegal activities to cope with their stress. Bolas and colleagues (2007) found that some expressed anger and frustrations, much like the youth in the current study who reportedly yelled and became angry when they did not have time for themselves. Moreover, this study showed some evidence for internalized stress as did other studies with YCs (Bolas et al., 2007; Cree, 2003; Early et al., 2006; Stamatopoulos, 2018). In other (very few) cases, instead of overidentification with emotions, the lack of time was manifested 
through some level of understanding and coping with their situation, as was the case with one participant who described that it was okay if she missed socializing, because she will see her friends at school. This complemented findings from Stamatopoulos' study (2018), where YCs reportedly chose to use another setting (like school) to gain back some social opportunities when they were anxious about "missing out" (in this case, hanging out with friends, which can be seen as a self-caring opportunity). Hence, accepting the fact that sometimes there would not be time for self-care could be their way of coping with the demands of their everyday lives. Although acceptance with one's caregiving role has been established in previous studies (Pakenham et al., 2007; Smyth et al., 2011a, 2011b), there are no studies, to my knowledge, that have examined this sense of 'acceptance' for lacking the time to self-care. Future studies could explore whether this acceptance is used as a coping strategy or may be a protective factor against 'compassion fatigue'.

Finally, almost all of the YCs in the current study showed aspects of common humanity, instead of isolation, perhaps due to the fact that they were a part of a support program with other YCs. For so many YCs, who are not a part of a program, caregiving can become an isolating experience (Ali et al., 2012; Bolas et al., 2007; Szafran et al., 2016). By becoming a part of a support program, it was not a surprise that YCs experienced a safe space, validation, and support (Richardson et al., 2009; Smyth, et al., 2011a, 2011b). With that, they also sensed right away that they were not alone and that others experienced the same hardships as them. These results paralleled the experiences of adult informal caregivers who said that they have gained comfort and understanding that others went through similar situations, reassuring to them that they were not alone (Williams et al., 2014a, 2014b).

This study further examined the role of supports for self-compassion. Results indicated that while some parents promoted self-compassion, others did not. The variability in parental support for self-compassion could simply be a function of individual differences in parents or parenting style differences, busyness level, quality of the relationship, and/or the nature of the illness or disability. For instance, it was evident from the results that some parents not only lacked time, but also may have assumed that their children were fine and had enough time for themselves. One YC may have even used a coping strategy to validate to herself that she is doing okay without her parents monitoring her condition. Conversely, others did not acknowledge this need for "alone time", which could be due to differences in everyday demands, seriousness of the illness, and unavailability of a parent due to work-related pressures. This complemented Stamatopoulos' (2018) findings, in which some YCs reported that their parents "pull out the caring card" (p. 196) when they asked for some alone time, and depending on the circumstances, parents denied their requests, thereby contributing to added familial strain. Given the great deal of variability, these findings should be taken lightly, especially because the present study did not collect data from parents to validate these results. Therefore, future studies should examine how the parental role could facilitate self-compassion in YCs' lives and assess parent' views, in addition to YCs, to gain a more comprehensive understanding of how they promote or discourage self-compassion.

Similarly, the role of support programs was examined in shaping self-compassion. Using YC programs as respite or "time out" is a common finding in literature (Richardson et al., 2009; Smyth et al., 2011a, 2011b). Additionally, it was special for them to have friends who go through similar experiences, which complemented previous studies (Richardson et al., 2009; Smyth et al., 2011a, 2011b). Having the opportunity to minimize their isolation through peer support and finding out that others go through similar situations may enhance their understanding of 'common humanity', thereby contributing to higher self-compassion, as previously discussed. However, this study revealed another contradiction. Despite the programs' ability to offer respite and teach skills to the youth, the YCs in the current study showed low selfcompassion rates. Thus, it could be beneficial for young carer organizations to evaluate whether their programs help to enhance self-compassion and further examine whether youth in the programs follow a self-care plan.

In summary, showing compassion for others may come with costs to one's own ability to show self-compassion. Despite this, being in a support program helped them establish connections with others and possibly, helped them be more engaged in self-care. This could be their first step towards building self-compassion.

\section{Implications}

This study yielded important results that could further contribute to improving support services and helping to guide parents in supporting self-compassion in their children. First, these focus groups revealed that YCs' self-compassion was low. This finding could help service providers to start cultivating self-compassion in youth as young as 12 . Past studies found that self-compassion could be a teachable skill (Neff \& Germer, 2012), and thus starting to address it with caregiving youth earlier could better equip them to self-care. Second, this study showed that YCs identified the caregiving role as a barrier to self-care and self-compassion. Given they already lack time, teaching self-compassion should not feel like an extra task and instead could be offered during regular program hours with some program modifications. For example, some lessons or intervention plans for YCs' 
self-compassion could include replacing self-judgement with self-kindness or introducing mindfulness to cope with emotional and physical stressors.

Furthermore, it is imperative to teach parents how to promote self-compassion in their children. This study showed that added tensions arose from having different definitions of self-care or self-compassion, from assuming the children are fine, and from being inconsistent with allowance of free time. Therefore, it would be important for parents to regularly 'check in' with their children, set expectations, monitor everyone's needs, and establish a balance, which could then make YCs feel less guilty about taking a break and furthermore, mitigate some familial conflicts (McDonald et al., 2010).

\section{Strengths and Limitations}

The current focus groups were held with YCs from support programs. This presented some limitations and strengths. It could be argued that YCs' recollections of self-caring practices were due to their participation in support programs that specifically aimed to reduce their stress. Therefore, it could be that their account of self-caring behaviours was related to what they have been taught in the programs. Given YCs were recruited from support programs, they might have had a chance to learn better coping tools than other YCs who might have been more isolated and hidden.

Although it presents a limitation, accessing support groups, where YCs know one another, was beneficial as it yielded rich qualitative content that otherwise would not have been possible to attain given this population is often hidden and private (Bolas et al., 2007; Kennan et al., 2012; Warren, 2008). It also helped to gain some insight into what it meant for identified YCs to be self-carers. Moreover, the youth in these focus groups had low self-compassion, thus suggesting they did not represent a more resilient group.

Finally, this study was also limited to only those YCs who have chosen to share their stories; thus, it did not capture the voices of the ones who remained quiet during the focus groups or those who chose not to participate in this study.

\section{Conclusion}

This was the first study, to our knowledge, to have examined self-compassion in caregiving youth. The results of this study helped to expand the current knowledgebase on YCs' self-compassion rates. Results revealed that in addition to being YCs and showing compassion towards their loved ones, they reported to self-care. They spoke about their lack of time to be able to self-care in relation to their caregiving role. There was evidence of low self-compassion; YCs had difficulty coming in terms with or understanding self-compassion. Their accounts were filled with feelings of selfishness, guilt, conflict, and many other aspects that directly minimized self-compassion. Their engagement in the support program has helped them obtain one aspect of self-compassion, common humanity, which protected them against possible isolation. These findings could be integrated into support programs that would help to increase self-compassion in youth who, without a doubt, offer a great deal of compassion to others, despite accumulating some costs to themselves.

Funding This study was not funded.

\section{Declarations}

Conflict of interest The authors declare that they have no conflict of interest.

Ethical Approval All procedures performed in this study were in accordance with the ethical standards of Brock University and the Research Ethics Board.

Consent to Participate Informed consent was obtained from all individual participants included in the study.

\section{References}

Acton, G. J. (2002). Health-promoting self-care in family caregivers. Western Journal of Nursing Research, 24(1), 73-86. https://doi. org/10.1177/01939450222045716

Ali, L., Ahlstrom, B. H., Krevers, B., \& Skarsater, I. (2012). Daily life for young adults who care for a person with mental illness: A qualitative study. Journal of Psychiatric and Mental Health Nursing, 19(7), 610-617. https://doi.org/10.1111/j.1365-2850. 2011.01829.x

Andrews, H., Tierney, S., \& Seers, K. (2020). Needing permission: The experience of self-care and self-compassion in nursing: A constructivist grounded theory study. International Journal of Nursing Studies, 101, 1-10. https://doi.org/10.1016/j.ijnurstu. 2019.103436

Areguy, F., Mock, S. E., Breen, A., Van Rhijn, T., Wilson, K., \& Lero, D. S. (2019). Communal orientation, benefit-finding, and coping among young carers. Child \& Youth Services, 40(4), 363-382. https://doi.org/10.1080/0145935X.2019.1614906

Banks, P., Cogan, N., Deeley, S., Hill, M., Riddell, S., \& Tisdall, K. (2001). Seeing the invisible children and young people affected by disability. Disability \& Society, 16(6), 797-814. https://doi.org/ 10.1080/09687590120083967

Banks, P., Cogan, N., Riddell, S., Deeley, S., Hill, M., \& Tisdall, K. (2002). Does the covert nature of caring prohibit the development of effective services for young carers? British Journal of Guidance \& Counselling, 30(3), 229-246. https://doi.org/10.1080/ 030698802100002281 
Berardini, Y., Volk, T., Chalmers, H., \& Kalkman, K. (in press). Is there a genetic predisposition to caregiving? In V. Marinos, S. Pomerantz, R. Raby, C. Tardif-Williams, \& D. Zinga (Eds.), Conceptualizing children and youth: Contexts, constraints, and agency. Athabasca Press

Bleakney, A. (2014). Spotlight on Canadians: Results from the General Social Survey. Young Canadians Providing Care. Retrieved April 16th, 2020 from http://www.statcan.gc.ca/pub/89-652-x/89-652x2014003-eng.htm

Bolas, H., Wersch, A. V., \& Flynn, D. (2007). The well-being of young people who care for a dependent relative: An interpretative phenomenological analysis. Psychology and Health, 22(7), 829-850. https://doi.org/10.1080/14768320601020154

Braun, V., \& Clarke, V. (2006). Using thematic analysis in psychology. Qualitative Research in Psychology, 3(2), 77-101. https://doi.org/ 10.1191/1478088706qp063oa

Cassidy, T., \& Giles, M. (2013). Further exploration of the Young Carers Perceived Stress Scale: Identifying a benefit-finding dimension. British Journal of Health Psychology, 18(3), 642655. https://doi.org/10.1111/bjhp.12017

Chalmers, H., \& Lucyk, L. (2012). The impact of caregiving: Is it who I am or what I do? Child and Youth Care Practice, 25(2), 37-46.

Chan, S. M., \& Chau, H. Y. S. (2010). Growing up with a parent with schizophrenia: What children say they need. Journal of Children's Services, 5(4), 31-42. https://doi.org/10.5042/jcs.2010.0693

Charles, G. (2011). Bringing young carers out of the shadows. Reclaiming Children \& Youth, 20(3), 26-30.

Charles, G., Stainton, T., \& Marshall, S. (2009). Young carers: Mature before their time. Reclaiming Children \& Youth, 18(2), 38-41.

Coleman, C., Martensen, C., Scott, R., \& Indelicato, N. A. (2016). Unpacking self-care: The connection between mindfulness, selfcompassion, and self-care for counselors. Counseling \& Wellness: A Professional Counseling Journal, 5, 1-8.

Collins, J., \& Bayless, S. (2013). How caring for a parent affects the psychological development of the young. Nursing Children and Young People, 25(10), 16-21. https://doi.org/10.7748/ncyp2013. 12.25.10.16.e351

Cree, E. V. (2003). Worries and problems of young carers: Issues for mental health. Child and Family Social Work, 8(4), 301-309. https://doi.org/10.1046/j.1365-2206.2003.00292.x

Dewar, B., Adamson, E., Smith, S., Surfleet, J., \& King, L. (2014). Clarifying misconceptions about compassionate care. Journal of Advanced Nursing, 70(8), 1738-1747. https://doi.org/10.1111/ jan. 12322

Doutre, G., Green, R., \& Knight-Elliott, A. (2013). Listening to the voices of young carers using interpretative phenomenological analysis and a strengths-based perspective. Educational \& Child Psychology, 30(4), 30-43.

Earley, L., Cushway, D., \& Cassidy, T. (2007). Children's perceptions and experiences of care giving: A focus group study. Counselling Psychology Quarterly, 20(1), 69-80. https://doi.org/10.1080/ 09515070701217830

Early, L. D., Cushway, D., \& Cassidy, T. (2006). Perceived stress in young carers: Development of a measure. Journal of Child and Family Studies, 15(1), 169-180. https://doi.org/10.1007/ s10826-005-9011-z

Fereday, J., \& Muir-Cochrane, E. (2006). Demonstrating rigor using thematic analysis: A hybrid approach of inductive and deductive coding and theme development. International Journal of Qualitative Methods, 5(1), 80-92. https://doi.org/10.1177/1609406906 00500107

Figley, C. R. (2002). Compassion fatigue: Psychotherapists' chronic lack of self care. Psychotherapy in Practice, 58(11), 1433-1441. https://doi.org/10.1002/jclp.10090
Fives, A., Kennan, D., Canavan, J., \& Brady, B. (2013). Why we still need the term 'young carer': Findings from an exploratory study of young carers in Ireland. Critical Social Work, 14(1), 49-61. https://doi.org/10.22329/csw.v14i1.5872

Gonyea, J. G., Paris, R., \& de Saxe Zerden, L. (2008). Adult daughters and aging mothers: The role of guilt in the experience of caregiver burden. Aging \& Mental Health, 12(5), 559-567. https://doi.org/ 10.1080/13607860802343027

Gough, G., \& Gulliford, A. (2020). Resilience amongst young carers: Investigating protective factors and benefit-finding as perceived by young carers. Educational Psychology in Practice. https://doi. org/10.1080/02667363.2019.1710469

Hamilton, M. G., \& Adamson, E. (2013). Bounded agency in young carers' lifecourse-stage domains and transitions. Journal of Youth Studies, 6(1), 101-117. https://doi.org/10.1080/13676261.2012. 710743

Hospice Toronto Annual Report 2018-2019. Retrieved July 19th, 2021 from https://hospicetoronto.ca/care/wp-content/uploads/2020/07/ HospiceTO-2018AR-web.pdf

Kennan, D., Fives, A., \& Canavan, J. (2012). Accessing a hard to reach population: Reflections on research with young carers in Ireland. Child and Family Social Work, 17(3), 275-283. https://doi.org/ 10.1111/j.1365-2206.2011.00778.x

Kitzinger, J. (2005). Focus group research: Using group dynamics to explore perceptions, experiences and understandings. In I. Holloway (Ed.), Qualitative research in health care (pp. 56-70). Open University Press.

Krueger, R. A. (1994). Focus groups: A practical guide for applied research (2nd ed.). Sage.

Lakman, Y. (2015). Profiling young carers' lives: An examination of individual, family, and social contexts.Unpublished master's thesis, Brock University.

Lakman, Y., \& Chalmers, H. (2019). Psychosocial comparison of carers and non-carers. Journal of Child and Youth Services, 40(2), 200-219. https://doi.org/10.1080/0145935x.2018.1553614

Lakman, Y., Chalmers, H., \& Sexton, C. (2017). Young carers' educational experiences and support: A road map for the development of school policies to foster academic success. Alberta Journal of Educational Research, 63(1), 1-12.

Lewis, M. (2019). Young carers initiative-powerhouse project year end report [Unpublished Report].

Liamputtong, P. (2011). Focus group methodology: Principles and practice. SAGE Publications Ltd. https://doi.org/10.4135/97814 73957657

Lim, D., \& DeSteno, D. (2016). Suffering and compassion: The links among adverse life experiences, empathy, compassion, and prosocial behavior. Emotion. https://doi.org/10.1037/emo0000144 Advance online publication.

Lloyd, K. (2013). Happiness and well-being of young carers: Extent, nature and correlates of caring among 10 and 11 year old school children. Journal of Happiness Studies, 14(1), 67-80. https://doi. org/10.1007/s10902-011-9316-0

Losada, A., Marquez-Gonzalez, M., Penacoba, C., \& Romero-Moreno, R. (2010). Development and validation of the Caregiver Guilt Questionnaire. International Psychogeriatrics, 22(4), 650-660. https://doi.org/10.1017/S1041610210000074

Macedonia, M. F. (2018). Self-care and self-compassion of disaster responders: Predictors of resilience [Doctoral dissertation, Antioch University]. Retrieved May 4th, 2020 from https://aura.antio ch.edu/etds/431/

McDonald, J., Cumming, J., \& Dew, K. (2009). An exploratory study of young carers and their families in New Zealand. Journal of Social Sciences, 4(2), 115-129. https://doi.org/10.1080/11770 83X.2009.9522448

McDonald, J., Dew, K., \& Cumming, J. (2010). Change and adaptation in families with young carers. Australian Journal of Social 
Issues, 45(4), 459-475. https://doi.org/10.1002/j.1839-4655.2010. tb00192.x

Metzing-Blau, S., \& Schnepp, W. (2008). Young carers in Germany: To live on as normal as possible- a grounded theory study. $B M C$ Nursing, 7(15), 1-9. https://doi.org/10.1186/1472-6955-7-15

Miles, M., Huberman, M., \& Saldana, J. (2019). Qualitative data analysis: A methods sourcebook (4th ed.). Sage Publishing.

Mills, J. (2018). Self-care, self-compassion, and compassion for others. Doctoral dissertation, University of Sydney. Retrieved May 4th, 2020 from https://ses.library.usyd.edu.au/handle/2123/18395

Mills, J., Wand, T., \& Fraser, J. A. (2018). Exploring the meaning and practice of selfcare among palliative care nurses and doctors: A qualitative study. BMC Palliative Care, 17(63), 1-12. https://doi. org/10.1186/s12904-018-0318-0

Moore, T., McArthur, M., \& Morrow, R. (2009). Attendance, achievement and participation: Young carers' experiences of school in Australia. Australian Journal of Education, 53(1), 5-18. https:// doi.org/10.1177/000494410905300102

Nagl-Cupal, M., Daniel, M., Koller, M. M., \& Mayer, H. (2014). Prevalence and effects of caregiving on children. Journal of Advanced Nursing, 70(10), 2314-2325. https://doi.org/10.1111/jan.12388

Nagl-Cupal, M., Metzing, S., \& Mayer, H. (2015). Experiences of being a former young carer: Effects in the transition into adulthood and in the present life situation. Revista Eletrônica De Enfermagem, 17(4), 1-10. https://doi.org/10.5216/ree.v17i4.34350

Neff, K. (2003). The development and validation of a scale to measure self-compassion. Self and Identity, 2, 223-250. https://doi.org/10. 1080/15298860390209035

Neff, K. D. (2003). Self-compassion: An alternative conceptualization of a healthy attitude toward oneself. Self and Identity, 2, 85-10. https://doi.org/10.1080/15298860309032

Neff, K. D., \& Germer, C. K. (2012). A pilot study and randomized controlled trial of the mindful self-compassion program. Journal of Clinical Psychology, 69(1), 28-44. https://doi.org/10.1002/jclp. 21923

Neff, K. D., \& McGehee, P. (2010). Self-compassion and psychological resilience among adolescents and young adults. Self and Identity, 9(3), 225-240. https://doi.org/10.1080/15298860902979307

Neff, K. D., Rude, S. S., \& Kirkpatrick, K. (2007). An examination of self-compassion in relation to positive psychological functioning and personality traits. Journal of Research in Personality, 41, 908-916. https://doi.org/10.1016/j.jrp.2006.08.002

Neff, K. D., \& Vonk, R. (2009). Self-compassion versus global selfesteem: Two different ways of relating to oneself. Journal of Personality, 77, 23-50. https://doi.org/10.1111/j.1467-6494.2008. 00537.x

Onwuegbuzie, A. J., Dickinson, W. B., Leech, N. L., \& Zoran, A. G. (2009). A qualitative framework for collecting and analyzing data in focus group research. International Journal of Qualitative Methods, 8(3), 1-21. https://doi.org/10.1177/1609406909 00800301

Pakenham, K. I., Chiu, J., Bursnall, S., \& Cannon, T. (2007). Relations between social support, appraisal and coping and both positive and negative outcomes of young carers. Journal of Health Psychology, 12(1), 89-102. https://doi.org/10.1177/1359105307 071743

Parveen, S., Morrison, V., \& Robinson, C. A. (2011). Ethnic variations in the caregiver role: A qualitative study. Journal of Health Psychology, 16(6), 862-872. https://doi.org/10.1177/1359105310 392416

Polkki, P., Ervast, S. A., \& Huupponen, M. (2004). Coping and resilience of children of a mentally ill parent. Social Work in Heath Care, 39(1-2), 151-163. https://doi.org/10.1300/J010v39n01_10

Richardson, K., Jinks, A., \& Roberts, B. (2009). Qualitative evaluation of a young carers' initiative. Journal of Child Health Care, 13(2), 150-160. https://doi.org/10.1177/1367493509102475
Sahoo, R., \& Suar, D. (2010). Influence of social environment on young carers, assistance and consequences of caregiving. Psychological Studies, 55(4), 323-329. https://doi.org/10.1007/ s12646-010-0041-2

Sawatzky, J. E., \& Flower-Kerry, S. (2003). Impact of caregiving: Listening to the voice of informal caregivers. Journal of Psychiatric and Mental Health Nursing, 10(3), 277-286. https://doi.org/10. 1046/j.1365-2850.2003.00601.x

Sexton, C. (2017). Caregiver stress: An exploration of stressors and coping strategies Among young carers [Unpublished master's thesis]. Brock University

Smyth, C., Blaxland, M., \& Cass, B. (2011). 'So that's how I found out I was a young carer and that I actually had been a carer most of my life': Identifying and supporting hidden young carers. Journal of Youth Studies, 14(2), 145-160. https://doi.org/10.1080/13676 261.2010 .506524

Smyth, C., Cass, B., \& Hill, T. (2011). Children and young people as active agents in care-giving: Agency and constraint. Children and Youth Services Review, 33(4), 509-514. https://doi.org/10.1016/j. childyouth.2010

Stamatopoulos, V. (2015). One million and counting: The hidden army of young carers in Canada. Journal of Youth Studies, 18(6), 1-14. https://doi.org/10.1080/13676261.2014.992329

Stamatopoulos, V. (2018). The young carer penalty: Exploring the costs of caregiving among a sample of Canadian youth. Child \& Youth Services, 39(2-3), 180-205. https://doi.org/10.1080/0145935X. 2018.1491303

Szafran, O., Torti, J., Waugh, E., \& Duerksen, K. (2016). Former young carers reflect on their caregiving experience. Canadian Journal of Family and Youth, 8(1), 129-151. Retrieved April 16th, 2020, from http://ejournals.library.ualberta.ca/index/php/cjfy

Tate, R. H. (2015). Learning to be a cancer caregiver: The role of selfefficacy in caregiver strain. (Publication No. 10759946) [Doctoral dissertation, The Pennsylvania State University]. ProQuest LLC

Thomas, N., Stainton, T., Jackson, S., Cheung, W. Y., Doubtfire, S., $\&$ Webb, A. (2003). Your friends don't understand': Invisibility and unmet need in the lives of 'young carers. Child and Family Social Work, 8(1), 35-46. https://doi.org/10.1046/j.1365-2206. 2003.00266.x

Tong, A., Sainsbury, P., \& Craig, J. (2007). Consolidated criteria for reporting qualitative research (COREQ): A 32-item checklist for interviews and focus groups. International Journal for Quality in Health Care, 19(6), 349-357. https://doi.org/10.1093/intqhe/ mzm042

van Groenou, M. I. B., de Boer, A., \& Iedema, J. (2013). Positive and negative evaluation of caregiving among three different types of informal care relationships. European Journal of Ageing, 10, 301-311. https://doi.org/10.1007/s10433-013-0276-6

Warren, J. (2007). Young carers: Conventional or exaggerated levels of involvement in domestic and caring tasks? Children and Society, 21(2), 136-146. https://doi.org/10.1111/j.1099-0860.2006. 00038.x

Warren, J. (2008). Young carers: Still 'hidden' after all these years? Research, Policy, and Planning, 26(1), 45-56.

Williams, A. M., Wang, L., \& Kitchen, P. (2014). Differential impacts of care-giving across three caregiver groups in Canada: End-oflife care, long-term care and short-term care. Health and Social Care in the Community, 22(2), 187-196. https://doi.org/10.1111/ hsc. 12075

Williams, K. L., Morrison, V., \& Robinson, C. A. (2014). Exploring caregiving experiences: Caregiver coping and making sense of illness. Aging \& Mental Health, 18(5), 600-609. https://doi.org/ 10.1080/13607863.2013.860425

Publisher's Note Springer Nature remains neutral with regard to jurisdictional claims in published maps and institutional affiliations. 